\title{
Acute cholecystitis and cholelithiasis developed after esophagectomy
}

\author{
M itsuo Tachibana MD, Shoichi Kinugasa MD, Hiroshi Yoshimura MD, Dipok Kumar Dhar MD, Shuhei U eda MD, \\ Toshiyuki Fujii MD, Takeru Nakamoto MD, Ioannis Kyriazanos MD, N aofumi Nagasue MD
}

\begin{abstract}
M Tachibana, S Kinugasa, H Yoshimura, et al. A cute cholecystitis and cholelithiasis developed after esophagectomy. C an J G astroenterol 2003;17(3):175-178.
\end{abstract}

BACKGROUND: A Ithough the prevalence of gallstone disease after gastrectomy is reported to be high, its prevalence after esophagectomy is scarcely reported.

MATERIA LS A N D METH ODS: G allbladder disease following an esophagectomy was prospectively evaluated in 237 patients with esophageal cancer by abdominal ultrasonography twice a year up to five years postoperatively. The median follow-up period was 18.6 months.

RESU LT S: O ne patient (0.4\%) developed acute acalculous cholecystitis postoperatively, and 13 patients (5.5\%) developed gallstone disease during the follow-up period. $N$ ine $(69 \%)$ of these 13 patients developed gallstone disease within two years, and another two patients developed the disease three years after esophagectomy. A nother patient developed gallbladder debris at 35 months postoperatively, and one developed gall lbladder polyps at 33 months. Seven of the 13 patients with gallstone disease underwent cholecystectomy between 13 and 125 months after esophagectomy: two developed acute cholecystitis; two had associated common bile duct stones; the remaining three patients had upper abdominal pain. $\mathrm{N}$ ine of the 13 patients who developed gallstone disease showed a history of alcoholism, whereas only 81 of 224 patients without gallstone disease had a similar history $(P<0.05)$.

CON C LU SION : A certain number of patients with esophageal carcinoma and a history of alcoholism develop cholelithiasis within three years after esophagectomy, and subsequently undergo cholecystectomy during the follow-up period.

Key Words: Alcoholism; Cholecystitis; Esophageal cancer; E sophagectomy; G allstone

\section{Cholécystite aiguë et cholélithiase par suite d'une oesophagectomie}

CONTEXTE : Bien que la formation de calculs biliaires soit souvent signalée après une gastrectomie, on en fait rarement état après une oesophagectomie.

MÉT H ODE : N ous avons procédé à un suivi prospectif de la vésicule biliaire par échographie abdominale deux fois par année jusqu'à cinq ans après une oesophagectomie chez 237 patients opérés pour un cancer de I'œsophage. La durée médiane du suivi a été de 18,6 mois.

RÉSU LTATS : Un patient $(0,4 \%)$ a souffert d'une cholécystite non lithiasique aiguë après l'opération et 13 patients $(5,5 \%)$ ont accusé une lithiase biliaire durant le suivi : neuf ( $69 \%$ ), dans les deux ans suivant I'oesophagectomie et deux autres, dans les trois ans. D es débris de vésicule biliaire ont été observés chez un autre patient 35 mois après I'opération et des polypes sont apparus chez un autre au bout de 33 mois. Sept des treize patients présentant des calculs biliaires ont subi une cholécystectomie entre 13 et 125 mois après I'oesophagectomie : deux pour une cholécystite aiquë, deux autres pour une lithiase associée du cholédoque et les trois derniers pour des douleurs abdominales hautes. Sur les 13 patients souffrant de cholélithiase, 9 avaient des antécédents d'alcoolisme, tandis que 81 seulement en présentaient sur les 224 patients exempts de la maladie $(\mathrm{P}<0,05)$.

CONCLUSION : Un certain nombre de patients atteints d'un carcinome de l'œsophage et ayant des antécédents d'alcoolisme ont présenté une cholélithiase dans les trois ans suivant l'oesophagectomie et ont subi une cholécystectomie durant la période de suivi.
E sophageal carcinoma is one of the most malignant tumours, Eand has a dismal prognosis $(1,2)$. A mong the available treatment options, esophagectomy is the gold standard treatment for this disease. Since the early 1980s, three-field extensive lymph node dissection during esophagectomy has become a standard surgical procedure to obtain an accurate pathological staging, and has contributed much to improve surgical results in Japan (3-6) and in the W estern countries $(7,8)$. The overall five-year survival rate has gradually improved to over $40 \%$ (3-6). However, during the long term follow-up period, these esophagectomized patients often suffer from gallbladder disorders (9-11).
Since the first report of a possible association of gallstone disease with gastric surgery (12), an increased incidence of gallstones has been reported in patients after gastrectomy $(13,14)$. The increased prevalence of gallstone formation following gastrectomy was associated with the denervation of the vagal nerve, cholestasis and/or the extent of abdominal lymph node dissection (15-17). A Ithough the pathophysiology of gallstone formation after esophagectomy and gastrectomy might be identical, there has been little attention paid to gall bladder disorder after esophagectomy. To that end, in the present study, we have prospectively evaluated gallbladder disorders and gallstone formation after esophagectomy operation.

Second Department of Surgery, Shimane M edical U niversity, Enya-cho 89-1, Izumo 693-8501, Shimane, Japan

C orrespondence and reprints: D r M Tachibana, Second D epartment of Surgery, Shimane M edical U niversity, E nya-cho 89-1, Izumo 693-8501,

Shimane, Japan. Telephone +81-853-20-2232, fax +81-853-20-2229, e-mail nigeka35@shimane-med.ac.jp

Received for publication July 9, 2002. A ccepted D ecember 10, 2002 


\section{PATIENTS AN D METHODS}

Between January 1981 and A ugust 2001, 304 patients with primary esophageal carcinoma were admitted to the Second Department of Surgery, Shimane M edical U niversity, Japan. Of these patients, 248 without a history of previous gallstone disease underwent esophagectomy. All patients underwent abdominal ultrasonography (AUS) and computed tomography (CT) to rule out the presence of any gall lbladder disease before surgery.

The majority of the patients underwent a right transthoracic subtotal esophagectomy and dissection of the cervical (bilateral supraclavicular regions), mediastinal (periesophagus and around the trachea including recurrent laryngeal nerve nodes), and abdominal (perigastric region and around the celiac axis) lymph nodes. Reconstruction was usually carried out with a gastric tube through the retrosternal route and esophagogastrostomy was done through a cervical incision in the neck. The bilateral vagal nerves were divided at the level just below the tracheal bifurcation. Lymph node dissection around the hepatic pedicle was not routinely done.

A t the outpatient department, patients routinely underwent A U S by specialized radiologists twice a year until five years after the operation or until the last follow-up period. Gallstones were defined as strong echo with an acoustic shadow, and debris was defined as echogenic material without acoustic shadowing. W hen gallbladder disease was suspected by AUS, further investigation was done by CT and/or drip infusion cholangiography. The median follow-up time was 18.6 months, ranging from one to 249 months. 0 ne hundred forty-seven patients were followed at the outpatient department at one year after esophagectomy, 99 at two years, 76 at three years, 64 at four years, and 48 at five years following esophagectomy.

The standard $\chi^{2}$ test with Yates' correction was used for comparative analyses. The level of significance was $\mathrm{P}<0.05$.

\section{RESU LT S}

Synchronous gallstone disease was detected in 11 of the 248 patients who had undergone surgical resection (4.4\%). A total of $16(6.8 \%)$ of the remaining 237 patients developed gallbladder ailments during the follow-up period of the present study. O ne $(0.4 \%)$ developed postoperative acute acalculous cholecystitis after esophagectomy and 13 (5.5\%) developed gallstone disease during the follow-up period. A nother two patients had gallbladder ailments other than the gallstones or cholecystitis; one patient developed gallbladder debris at 35 months and one had gallbladder polyps at 33 months after esophagectomy, respectively (Figure 1). Twelve of the 13 patients with gallstone disease were men; the group of 13 patients had a mean age of $66 \pm 7$ years. M oreover, because all 13 patients who developed gallstones underwent radical esophagectomy with a curative intent ( $\mathrm{R} 0$ cases), the prevalence became $7.3 \%$ of $178 \mathrm{R} 0$ cases. The shortest period after which gallstones developed following esophagectomy was six months. The incidence was $8.3 \%$ in 156 patients who survived over six months after esophagectomy. The numbers of patients evaluated at the outpatient department were 147, 99, 76, 64, and 48 at the end of the first, second, third, fourth and fifth year, respectively. A mong these patients, four, five and two patients developed gallstones in the first, second and third year of the follow-up, respectively. There were no new cases in the fourth and fifth year of follow-up. One patient developed gallstones during each of the seventh and tenth year of follow-up (Figure 2).

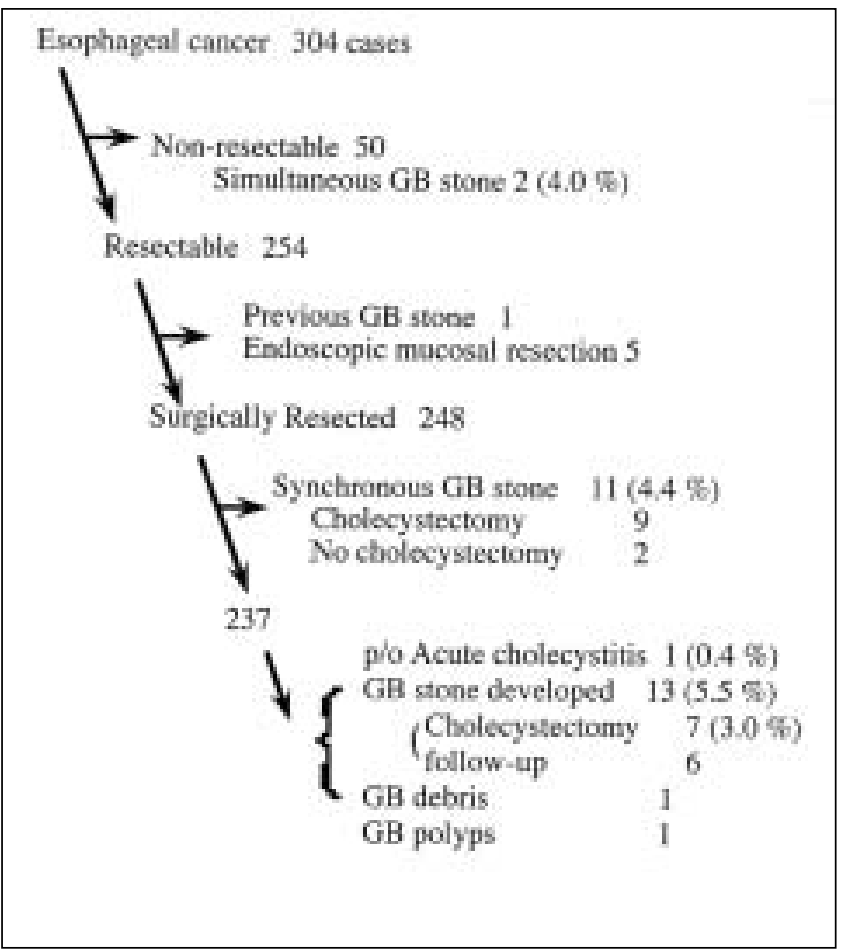

Figure 1) Patient algorithm. G B gallbladder; p/o Postoperative.

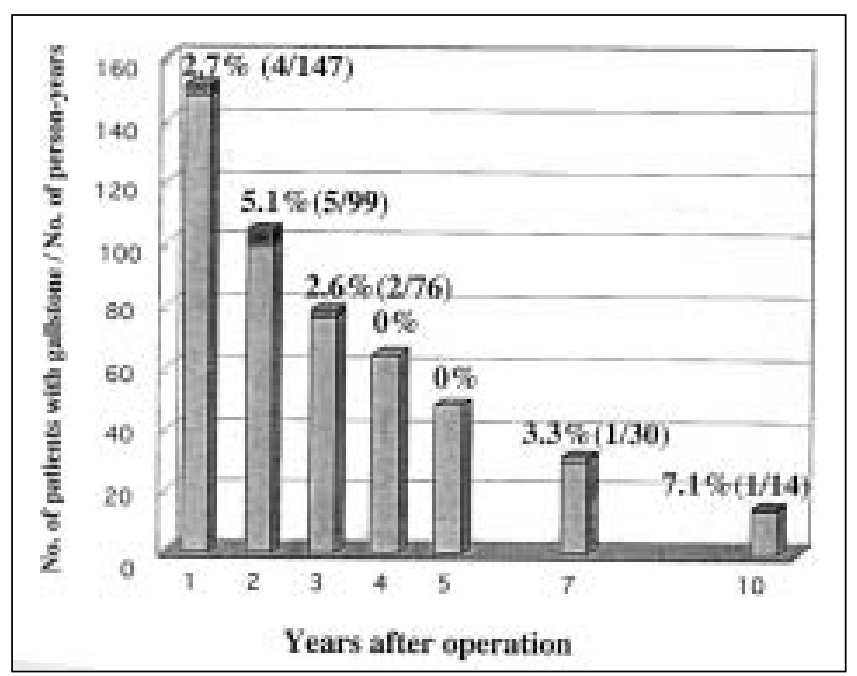

Figure 2) Yearly incidence of gallstone formation. The dark bar indicates the number of patients who developed gallstones over the number of patients followed up (thin bar) at each year after esophagectomy

O ne patient developed acute acalculous cholecystitis on the tenth postoperative day and immediately underwent percutaneous transhepatic gallbladder drainage. He made an uneventful recovery (Figure 3). O verall, nine (69\%) of the 13 patients developed gallstones within two years and another two at the third year after esophagectomy.

Seven (54\%) of the 13 patients with gallstone disease were treated surgically and six patients were treated conservatively. 


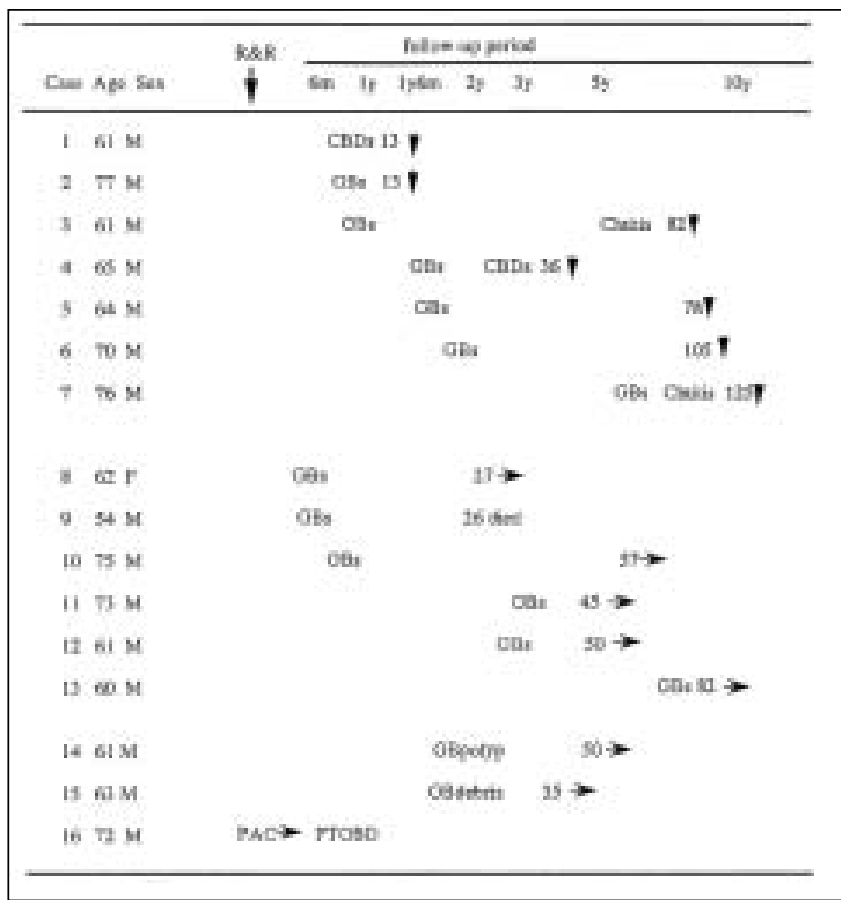

Figure 3) C linical outcomes of 16 patients who developed gallbladder ailments after esophagectomy. C BD s C ommon bile duct stone; $\mathrm{C}$ htitis Cholecystitis F Female; GBs Gallstones; $m$ month(s), M Male; y year(s); PA C Postoperative acute cholecystitis; PT G BD Percutaneous transhepatic gallbladder drainage; $R \& R$ Esophageal resection and reconstruction; $\downarrow C$ holecystectomy (with or without choledocholithotomy; $\rightarrow$ Follow up.

A mong those seven patients who were treated surgically, two patients underwent simultaneous common bile duct exploration due to the common bile duct stones. A nother two patients developed acute cal culous cholecystitis at 82 and 125 months, respectively, and underwent emergency cholecystectomy. A nother three patients underwent cholecystectomy due to upper abdominal pain (Figure 3). All stones were revealed to be pigment stones by macroscopic examination.

To determine risk factors of gallstone development after esophagectomy, the history of alcohol consumption was evaluated. $\mathrm{N}$ ine of the 13 patients who developed gallstones comsumed more than $80 \mathrm{~g}$ of alchol per day over 10 years, whereas only 81 of 224 patients without gallstones consumed this amount of alcohol $(P<0.05)$. There were no differences in age (63.4 \pm 7.1 years versus $63.7 \pm 8.6$ years, respectively), sex (male:female 12:1 versus 208:16, respectively), and body mass index (21.4 \pm 3.6 versus $20.5 \pm 2.8$, respectively) between the 13 patients who developed gallstones during the follow-up period and those 224 who did not. A history of smoking and the presence or absence of liver disease and diabetes mellitus also did not influence the incidence of postoperative gallstone formation.

\section{DISCUSSION}

A cute postoperative cholecystitis is an unusual but morbid complication following different surgical procedures $(9,10,15)$. Its prevalence is reported to be from $0.06 \%$ to $3.1 \%$, depending on the different primary surgical procedures $(9,15)$. A collective review from Japan (9) reported a preval ence of $0.06 \%$ of total number of operations and $0.09 \%$ of abdominal operations. A higher prevalence was reported after gastrectomy followed by esophagectomy operation. The prevalence of $0.4 \%$ as reported in the present study was comparable to those of previous studies. C auses of acute cholecystitis and gallstone formation include biliary stasis with distension of the gallbladder, prolonged fasting, anesthesia, vagotomy and dissection of the upper abdominal lymph nodes, particularly around the hepatic pedicle $(9,10,15)$. Early surgical intervention such as cholecystectomy or percutaneous transhepatic gallbladder drainage is indicated $(9,10,15)$.

The prevalence of gallstones after gastrectomy is reported to be from $12 \%$ to $20 \%$, depending on the duration of the follow-up period, the type of gastrectomy (partial versus total), the presence or absence of vagotomy and the extent of lymph node dissection (15-17). There have been few reports describing different kinds of gallbladder ailments during the postoperative period following esophagectomy (9-11); however, the prevalence of gallstones after this operation has not been reported. In the present study, the prevalence of synchronous gallstones was $4 \%$ in the nonresectable group and $5.5 \%$ in those undergoing surgical resection, showing no significant difference. The prevalence of gallstones in the general middleage population in Japan is about $5 \%$ (18) and increases to about $10 \%$ in the elderly (19). These results indicate that the prevalence of gallstones after esophagectomy may be low compared with that after gastrectomy, and may be almost the same compared with that of the general population. The reasons for a lower prevalence of gallstone formation after esophagectomy compared with that after gastrectomy remain speculative; however, there are possible explanations. First, the duration of follow-up was relatively short for the esophagectomized patients compared with that of the gastrectomized patients. Because the number of long term survivors after esophagectomy was relatively small compared with those after gastrectomy, the potential number of patients after esophagectomy became less during the long term follow-up period. Second, unlike during a gastrectomy operation, no patients with esophageal cancer underwent routine lymph node dissection around the hepatic pedicle. Cholestasis due to lymph node dissection is a rare cause of gallstone formation. H owever, the finding that all stones in the present study were pigment stones indicates that cholestasis may be the reason for their development. A vagotomy procedure during the esophagogastrectomy operation may produce biliary stasis and stone formation.

W hether cholecystectomy is necessary for asymptomatic gallstone disease is still debatable. The incidence of asymptomatic patients with gallstones who became symptomatic was $10 \%$ to $18 \%$ over a five to 15 year follow-up period (20). The present study showed that $54 \%$ of 13 patients underwent cholecystectomy, indicating that gallstones that developed after esophagectomy should not be treated as they are in the general population. Moreover, one of the risk factors of gallstone formation in patients undergoing esophagectomy was a history of alcohol consumption. The association between alcohol intake and gallstone disease was previously characterized (21), and, similarly, al cohol may contribute to gallstone formation by altering biliary sphincter motility (22). Therefore, we believe that esophagectomized patients should be carefully followed for gallstone formation when the patient discloses a history of alcohol consumption. 


\section{CONCLUSIONS}

$\mathrm{O}$ ur results indicate that a certain number of esophageal carcinoma patients develop cholelithiasis within three years after esophagectomy, and half of those subsequently undergo cholecystectomy operation. Esophagectomized patients should be carefully followed for gallstone development at the outpatient department when he or she has a history of alcohol consumption.

\section{REFEREN CES}

1. lizuka T, I sono K, Kakegawa T, W atanabe H. Parameters linked to ten-year survival in Japan of resected esophageal carcinoma. C hest 1989;96:1005-101.

2. Daly JM, Karnell LH, M enck HR. N ational cancer data base report on esophageal carcinoma. Cancer 1996;78:1820-8.

3. Isono K, Sato H, N akayama K. Results of a nationwide study on the three-field lymph node dissection of esophageal cancer. Oncology 1991;48:411-20.

4. A kiyama $\mathrm{H}$, Tsurumaru M, U dagawa H, Kajiyama Y. Radical lymph node dissection for cancer of the thoracic esophagus. A nn Surg 1994;220:364-73.

5. Fujita H, Kakegawa T, Yamana $H$, et al. M ortality and morbidity rates, postoperative course, quality of life, and prognosis after extended radical lymphadenectomy for radical lymphadenectomy for esophageal cancer. A nn Surg 1995;222:654-62.

6. Tachibana M , Kinugasa S, Dhar DK, et al. Prognostic factors after extended esophagectomy for squamous cell carcinoma of the thoracic esophagus. J Surg O ncol 1999;72:88-93.

7. Lerut T, Leyn PD, Coosemans W, Raemdonck DV, Scheys I, Saffre EL. Surgical strategies in esophageal carcinoma with emphasis on radical lymphadenectomy. A nn Surg 1992;216:583-90.

8. A Itorki N K, Skinner DB. O ccult cervical nodal metastasis in esophageal cancer: Preliminary results of three-field lymphadenectomy. J Thorac Cardiovasc Surg 1997;113:540-4.

9. Inoue T, M ishima Y. Postoperative acute cholecystitis: A collective review of 494 cases in Japan. Jpn J Surg 1988;18:35-42.

10. Paull DE. A cute cholecystitis in the immediate postoperative period following esophagogastrectomy. A m Surg 2001;67:97-9.

11. Collard JM, O tte JB, Reynaert M, M ichel L, C arlier MA, Kestens PJ. Esophageal resection and by-pass: A 6 year experience with a low postoperative mortality. W orld J Surg 1991;15:635-41.

12. Majoor CLH, Suren TJJ. G allbladder complications following resection of stomach for peptic ulcer. Br M ed J 1947:2:8-11.

13. Ikeda $Y$, Shinchi K, Kono S, Tsuboi K, Sugimachi K. Risk of gallstones following gastrectomy in Japanese men. Surg Today 1995;25:515-8.

14. Hauters $P$, de N eve de Roden A, Pourbaix A, A upaix F, C oumans $P$, Therasse $G$. C holelithiasis: A serious complication after total gastrectomy. Br J Surg 1988;75:899-900.

15. W u CC, Chen CY, W u T C, liu TJ, P'eng PK. Cholelithiasis and cholecystitis after gastrectomy for gastric carcinoma: A comparison of lymphadenectomy of varying extent. $H$ epatogastroenterology 1995;42:867-72

16. Kodama I, Yoshida C, Kofuji K, O hta J, A oyagi K, Takeda J. $\mathrm{G}$ allstones and gallbladder disorder after gastrectomy for gastric cancer. Int Surg 1996;81:36-9.

17. Inoue K, Fuchigami A, H igashide S, et al. G allbladder sludge and stone formation in relation to contractile function after gastrectomy: A prospective study. A nn Surg 1992;215:19-26.

18. Kameta $\mathrm{H}$. Present status the type of gallstones by classification in Japan. Tan to Sui 1991,12:1179-83. (in Japanese)

19. $\mathrm{N}$ omura $\mathrm{H}$, Kashiwagi $\mathrm{S}, \mathrm{H}$ ayashi $\mathrm{H}$, et al. Prevalence of gallstone disease in a general population of 0 kinawa, Japan. A $m$ J Epidemiol 1988;128:598-605.

20. Gibney EJ. A symptomatic gallstones. Br J Surg 1990;77:368-72.

21. Conte $D, B$ arisani $D, M$ andelli $C$, et al. Prevalence of cholelithiasis in alcoholic and genetic haemochromatotic cirrhosis. A Icohol 1993;28:581-4.

22. Tierney S, Q ian Z, Lipsett PA, Pitt HA, Lillemoe KD. Ethanol inhibits sphincter of $O$ ddi motility. J G astrointest Surg 1998;2:356-62. 


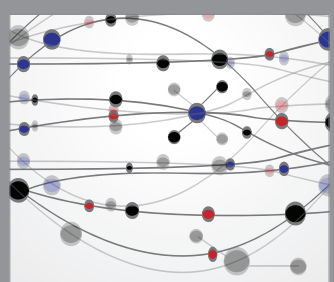

The Scientific World Journal
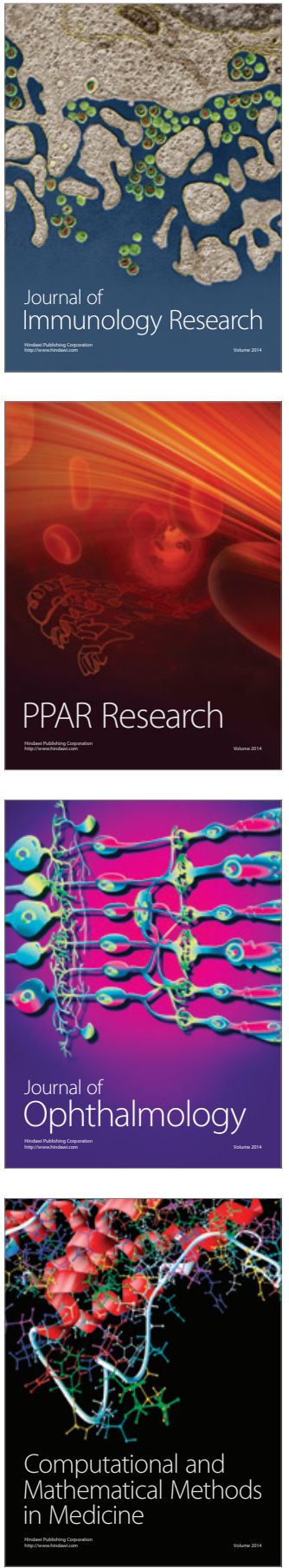

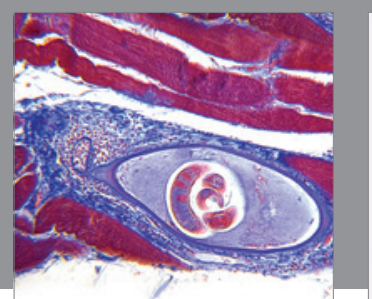

Gastroenterology Research and Practice

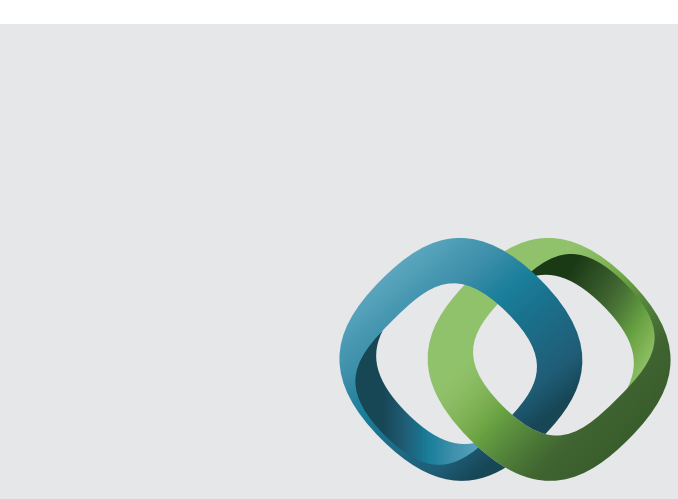

\section{Hindawi}

Submit your manuscripts at

http://www.hindawi.com
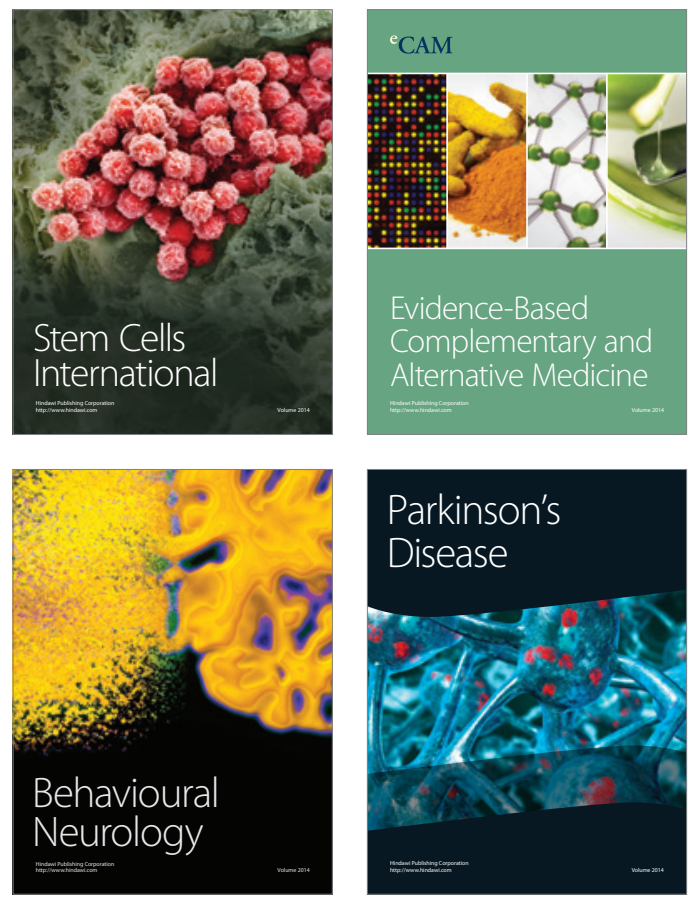
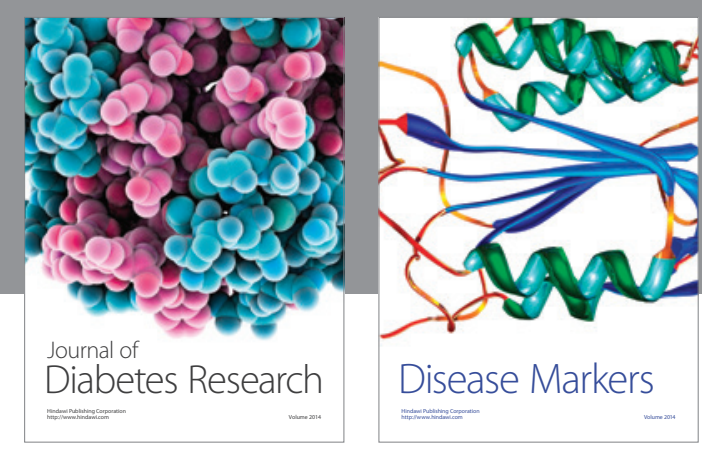

Disease Markers
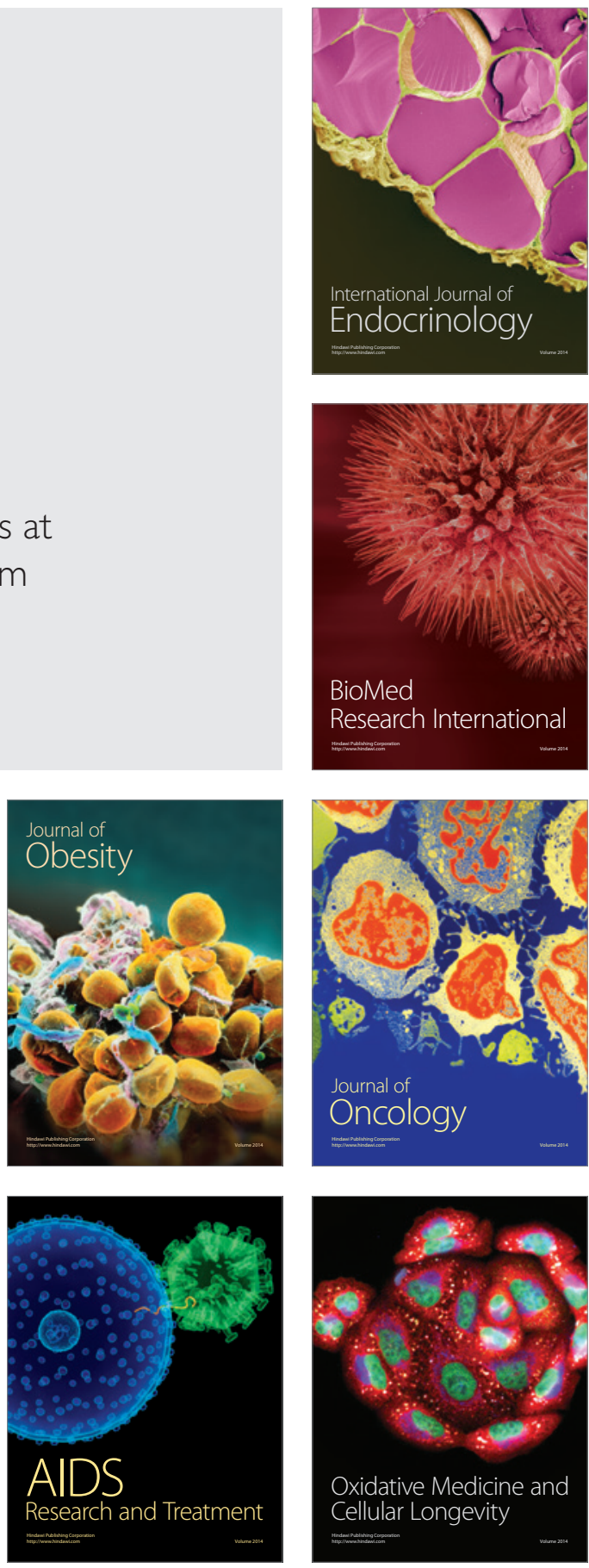